\title{
Frequency and antimicrobial resistance of bacteria isolated from oral and topical medicaments from Hilla, Iraq
}

\author{
Alaa H. Al-Charrakh \\ College of medicine, Babylon University, Iraq
}

\begin{abstract}
Introduction: The presence of microorganisms in pharmaceuticals is undesirable because they may cause spoilage of the product and may present an infection hazard to the consumers or patients.

Methodology: A total of 102 samples of oral and topical non-sterile pharmaceutical products were collected at random from different drug houses and pharmacies in Iraq, to investigate the microbial contamination of these products. Bacterial isolates recovered from these medicaments were subjected to susceptibility testing against various antibiotics by disk diffusion method according to Clinical and Laboratory Standards (CLSI) guidelines.

Results: The results revealed that the occurrence of Gram-positive bacteria was in oral and topical medicaments while Gram-negative bacteria were only detected in topical medicaments. More than $58 \%$ of Bacillus isolates were resistant to lincomycin and Bacillus mycoides isolates were resistant to beta-lactam antibiotics and trimethoprim-sulfamethoxazole. Staphylococcus spp. showed a relatively high resistance to ampicillin, amoxicillin, penicillin, tetracycline, and trimethoprim-sulfamethoxazole. S. epidermidis had the highest number of multi-resistant isolates. Furthermore, $87.5 \%$ of isolated Gram-negative rods showed high resistance to betalactam antibiotics and $75 \%$ of them were highly resistant to erythromycin. One isolate of Pseudomonas aeruginosa was the most resistant among all Gram-negative rod isolates.

Conclusion: The high rate of resistance to antimicrobial agents of bacterial isolates recovered from oral and topical medicaments in this study may indicate a widespread antibiotic resistance among bacteria isolated from different sources, including those of anthropological and environmental origin.
\end{abstract}

Key words: antibiotic resistance; bacteria; contamination; medicaments; Pseudomonas

J Infect Dev Ctries 2012; 6(6):489-494.

(Received 27 December 2010 -Accepted 15 March 2011)

Copyright (C) 2012 Al-Charrakh. This is an open-access article distributed under the Creative Commons Attribution License, which permits unrestricted use, distribution, and reproduction in any medium, provided the original work is properly cited

\section{Introduction}

Several papers have been published reporting the contamination of non-sterile pharmaceuticals with microorganisms [1-3]. The presence of microorganisms in pharmaceuticals is undesirable because they may cause spoilage of the product and may present an infection hazard to the consumers or patients. Several cases of infections caused by the administration of non-sterile medicaments with micro-organisms have been reported [4,5]. The probability of infection depends on a number of factors including the type of microorganism, the numbers present, the route of infection, and the health status of the host [6].According to these findings, many developed countries have adopted microbiological standards as well as the application of good manufacturing practices to guarantee the hygienic quality of the non-sterile medicaments $[7,8]$.
The number of bacterial strains capable of causing infections is increasing; many of them are resistant to one or more of the antibiotics used in therapy and this resistance constitutes an increasingly serious threat to the current antimicrobial agents' therapy [9]. The acquisition of resistance to the antimicrobial agents may be due to chromosomal mutation or plasmids that are capable of transfer from one strain of bacteria to another, even across the species barrier. Also, the resistance genes are found on mobile genetic elements called transposons [10]. Some transposons or plasmids have genetic elements termed "integrons" that enable them to capture exogenous genes. A number of genes may therefore be inserted into a given integron, resulting in resistance to multiple antimicrobial drugs [11]. 
Table 1. Number and percentage of contaminated samples of oral and topical medicaments

\begin{tabular}{|c|c|c|c|c|c|c|}
\hline \multirow{3}{*}{ Bacterial isolates } & \multicolumn{6}{|c|}{ Medicaments (No. of samples) } \\
\hline & \multicolumn{2}{|c|}{ Oral ( 85 ) } & \multicolumn{2}{|c|}{ Topical ( 17 ) } & \multicolumn{2}{|c|}{ Total ( 102 ) } \\
\hline & Number & $\%$ & Number & $\%$ & Number & $\%$ \\
\hline \multicolumn{7}{|l|}{ Gram+ ve rods: } \\
\hline Bacillus & 10 & 11.7 & 3 & 17.6 & 13 & 12.7 \\
\hline \multicolumn{7}{|l|}{ Gram+ ve cocci: } \\
\hline Staphylococcus & 7 & 8.2 & 2 & 11.7 & 9 & 8.8 \\
\hline Micrococcus & 2 & 2.3 & 1 & 5.8 & 3 & 2.9 \\
\hline \multicolumn{7}{|l|}{ Gram-ve rods: } \\
\hline Pseudomonas & & & 1 & 5.8 & 1 & 0.9 \\
\hline Escherichia coli & & & 1 & 5.8 & 1 & 0.9 \\
\hline Klebsiella & & & 1 & 5.8 & 1 & 0.9 \\
\hline Enterobacter & & & 1 & 5.8 & 1 & 0.9 \\
\hline
\end{tabular}

The importance of resistant environmental strains is that in certain favorable conditions they may transfer their resistant plasmids to the pathogenic strains. This problem is very serious, especially in hospitals where the environment can be a factor for the selection of multiple drug resistant strains [10]. If these resistant bacteria are present in the medicaments they may behave as opportunistic pathogens and initiate an infection, especially in immunocompromised patients.

The aim of this study was to investigate the microbial contamination of some non-sterile pharmaceuticals present in Iraq and study the susceptibility to selected antibiotics of bacterial isolates recovered from these medicaments.

\section{Methodology}

\section{Medicaments samples}

A total of 102 samples of oral and topical nonsterile pharmaceutical products were collected at random from different drug houses and pharmacies in Babylon province, Iraq. Excluded products were those that included antimicrobial agents and some syrups. Topical medicaments included 11 ointments, 2 creams, 2 lotions, and 2 pastes. Oral medicaments included 38 tablets, 8 pills, 16 capsules, 9 powders, 12 syrups, and 2 solutions. All the medicaments were registered trademark specialties.

To prepare the sample, 1 gram or $1 \mathrm{ml}$ each from two different containers of the same product were taken and mixed. These mixtures were then resuspended in $90 \mathrm{ml}$ of normal saline and decimal solutions were prepared. Oral medicaments were diluted in phosphate buffer solution.

\section{Bacterial isolates and susceptibility tests}

Aerobic viable bacteria were isolated by plating of decimal dilutions on the following culture media: nutrient agar, 5\% human blood agar, MacConkey's agar, and chocolate agar (Oxoid, Basingstoke, United Kingdom). Selected bacterial colonies were subcultured to tryptone soy agar slants and the organisms were identified to the level of species by using conventional biochemical tests [12] then the identification was confirmed using API system strips (Biomerieux, Marcy l'Etoile, France).

The resistance of the bacterial isolates to antimicrobial agents was determined by using the disk diffusion method [13] and interpreted according to Clinical and Laboratory Standards Institute (CLSI) guidelines [14].

The following antimicrobial agents were obtained (from Oxoid, Basingstoke, United Kingdom) as standard reference disks as known potency for laboratory use: penicillin $(\mathrm{P}), 10$ units; ampicillin (Amp), $10 \mu \mathrm{g}$; amoxicillin (Amx), $10 \mu \mathrm{g}$; cephalexin (K), $30 \mu \mathrm{g}$; cefotaxime (Ctx), $30 \mu \mathrm{g}$; ceftizoxime (Czx), $30 \mu \mathrm{g}$; gentamicin $(\mathrm{Gm}), 10 \mu \mathrm{g}$; streptomycin (S), $10 \mu \mathrm{g}$; erythromycin (E), $15 \mu \mathrm{g}$; Chloramphenicol (C), 30 $\mu \mathrm{g}$; tetracycline (Te), $30 \mu \mathrm{g}$; lincomycin (L), amount?; rifampicin (R) $5 \mu \mathrm{g}$; polymyxin B (PB), 300 units; bacitracin (B), $10 \mu \mathrm{g}$; and trimethoprim-sulfamethoxazole (SXT), 1.25$23.75 \mu \mathrm{g}$. 
All these tests were performed on plates of Muller-Hinton agar (Oxoid, Basingstoke, United Kingdom). Bacterial suspensions were adjusted with turbidty of 0.5 McFarland's nephlometer index (provided by Biomérieux, Marcy l'Etoile, France) and applied to the plates, which were dried in an incubator at $35^{\circ} \mathrm{C}$ for 15 minutes. Antimicrobial disks were placed on the agar with sterile forceps. The agar plates were incubated inverted at $35^{\circ} \mathrm{C}$ for 18 hours. Results were recorded by measuring the zone of inhibition (in millimeters) and interpreted according to Clinical and Laboratory Standards Institute guidelines [14].

\section{Results}

Isolation and identification of bacterial isolates

A total of 53 bacterial strains were isolated. Out of them, Gram-positive rods were the most commonly found in oral and topical medicaments $(12.7 \%)$ followed by Gram-positive cocci $(11.7 \%)$. Gram-negative rods were isolated only from topical medicaments. Topical medicaments showed high proportions of contaminated samples $(17.6 \%)$ and more bacterial genera than oral ones (Table 1). Three species of Bacillus were identified, the most frequent of which was $B$. licheniformis (Table 2). The most frequent species of Staphylococcus isolated from oral and topical medicaments was $S$. epidermidis. One isolate of $S$. aureus was detected in one sample of ointments (Table 3).

Three strains of Escherichia coli were found in one sample of topical medicaments whereas one isolate of Pseudomonas aeruginosa was detected in one sample of topical medicaments (Table 4).

\section{Resistance to the antimicrobial agents}

The antibiotic resistance patterns of the bacterial isolates recovered from oral and topical medicaments were determined (Tables 2, 3, and $4)$.

Bacillus isolates were resistant to lincomycin $(58.6 \%)$ and bacitracin $(20.6 \%)$ but they were all susceptible to gentamicin and pifampicin. $B$. mycoides showed the highest number of isolates resistant to penicillins, cephalosporins, and trimethoprim-sulfamethoxazole (STX), while Bacillus spp. isolates were susceptible to all these antimicrobial agents (Table 2).

A percentage of Staphylococcus isolates were resistant to Amp (72.7\%), Amx (63.6 \%), P $(54.5 \%)$, and $\operatorname{STX}(54.5 \%)$, but they were all susceptible to extended-spectrum beta-lactams (cefotaxime and ceftizoxime), aminoglycosides (gentamicin and streptomycin), and lincomycin.

Micrococcus strains were susceptible to all antimicrobial agents used in this study except strepyomycin and chloramphenicol.

A high percentage of Gram-negative rods strains were resistant to beta-lactams and erythromycin. $P$. aeruginosa isolate showed resistance to beta-lactams, gentamicin, and erythromycin (Table 4). E. aerogenes isolates showed resistance to beta-lactams, tetracycline, and streptomycin. Klebsiella pneumoniae isolate showed resistance to beta-lactams and erythromycin, as well as to extended-spectrum beta-lactams (Table 4).

\section{Discussion}

The results of this study showed that Bacillus species were the bacteria most frequently found in orally and topically administrated medicaments, and this observation agrees with the work of other investigators $[1,2]$.

The significant microbial contamination of non-sterile pharmaceuticals with these bacteria can be attributed to the wide distribution of Bacillus species in the soil, dust, air, and water and to the fact that they are resistant to environmental destructive factors [15]. Although the members of the genus Bacillus have been frequently considered as non-pathogenic, some authors have reported serious human infections associated with Bacillus spp., particularly in immunosuppressed patients [16].

Like Bacillus spp., Gram-positive cocci can survive in the environment and thus contaminate medicaments. S. epidermidis has been the most frequently isolated species from oral and topical medicaments in previous studies $[1,3)]$ Micrococcus spp. has also been isolated from liquid and solid drugs [1].

The isolation of $P$. aeruginosa from topical medicaments was similar to the findings presented by Spooner [5]. The contamination of the medicaments with these bacteria may pose an important and serious problem because it may generate severe infections to humans. de la Rosa and colleagues [1] found several Pseudomonas strains, but they did not isolate $P$. aeruginosa from the pharmaceuticals they studied.

In this study, other gram-negative rods isolated from non-sterile topical medicaments were E. coli, Klebsiella spp., and E. aerogenes. Similar finding have also been reported by other authors $[1,5,6]$. 
Table 2. Antibiotic resistance of Bacillus isolates recovered from medicaments

\begin{tabular}{|c|c|c|c|c|c|c|c|c|c|c|c|c|c|c|c|c|c|c|}
\hline \multirow[t]{2}{*}{ Species } & \multicolumn{3}{|c|}{ No. of isolates } & \multicolumn{15}{|c|}{ No. of resistant isolates } \\
\hline & Oral & Topical & Total & $\mathbf{P}$ & Amp & Amx & $\mathbf{K}$ & Ctx & $\mathbf{C z x}$ & Gm & $\mathbf{E}$ & $\mathbf{C}$ & Te & $\mathbf{R}$ & SXT & $\mathbf{L}$ & PB & B \\
\hline $\begin{array}{c}\text { B. } \\
\text { licheniformis }\end{array}$ & 2 & 4 & 6 & 1 & 1 & 1 & & & & & & 1 & & & & 3 & 1 & 3 \\
\hline B. mycoides & 2 & 3 & 5 & 4 & 3 & 3 & 2 & 1 & 2 & & & & 2 & & 3 & 2 & & \\
\hline Bacillus spp. & 12 & 6 & 18 & & & & & & & & & 3 & & & & 12 & & 3 \\
\hline Total No. & 18 & 11 & 29 & 5 & 4 & 4 & 2 & 1 & 2 & & & 4 & 2 & & 3 & 17 & 1 & 6 \\
\hline Total $\%$ & & & & 17.2 & 13.7 & 13.7 & 6.8 & 3.4 & 6.8 & & & 13.7 & 6.8 & & 10.3 & 58.6 & 3.4 & 20.6 \\
\hline
\end{tabular}

Table 3. Antibiotic resistance of Staphylococcus and Micrococcus isolates isolated from medicaments

\begin{tabular}{|c|c|c|c|c|c|c|c|c|c|c|c|c|c|c|c|c|c|c|}
\hline \multirow[t]{2}{*}{ Species } & \multicolumn{3}{|c|}{ No. of isolates } & \multicolumn{15}{|c|}{ No. of resistant isolates } \\
\hline & Oral & Topical & Total & $\mathbf{P}$ & Amp & $\operatorname{Amx}$ & $\mathbf{K}$ & Ctx & $\mathbf{C z x}$ & Gm & $\mathbf{S}$ & $\mathbf{E}$ & $\mathbf{C}$ & Te & $\mathbf{R}$ & SXT & $\mathbf{L}$ & $\mathbf{B}$ \\
\hline $\begin{array}{c}\text { Staphylococcus } \\
\text { epidermidis }\end{array}$ & 4 & 3 & 7 & 3 & 5 & 4 & & & & & & 1 & 2 & 4 & & 3 & & \\
\hline $\begin{array}{c}\text { Staphylococcus } \\
\text { aureus }\end{array}$ & & 1 & 1 & 1 & 1 & 1 & 1 & & & & & & & 1 & & 1 & & \\
\hline $\begin{array}{l}\text { Staphylococcus } \\
\text { spp. }\end{array}$ & 2 & 1 & 3 & 2 & 2 & 2 & & & & & & & & 1 & & 2 & & \\
\hline Micrococcus spp. & 2 & 3 & 5 & & & & & & & & 2 & & 2 & & & & & \\
\hline Total No. & 8 & 8 & 16 & 6 & 8 & 7 & 1 & & & & 2 & 1 & 4 & 6 & & 6 & & \\
\hline Total $\%$ & & & & 37.5 & 50 & 43.7 & 6.2 & & & & 12.5 & 6.2 & 25 & 37.5 & & 37.5 & & \\
\hline
\end{tabular}


Table 4. Antibiotic resistance of Gram-negative rods isolates recovered from topical medicaments

\begin{tabular}{|c|c|c|c|c|c|c|c|c|c|c|c|c|c|c|}
\hline \multirow{2}{*}{ Species } & \multirow{2}{*}{$\begin{array}{l}\text { No. of } \\
\text { isolates }\end{array}$} & \multicolumn{13}{|c|}{ No. of resistant isolates } \\
\hline & & $\mathbf{P}$ & Amp & Amx & $\mathbf{K}$ & Ctx & $\mathbf{C z x}$ & Gm & $\mathbf{S}$ & $\mathbf{E}$ & C & Te & $\mathbf{R}$ & SXT \\
\hline $\begin{array}{c}\text { Pseudomonas } \\
\text { aeruginosa }\end{array}$ & 1 & 1 & 1 & 1 & 1 & & & 1 & & 1 & & & & \\
\hline $\begin{array}{l}\text { Escherichia } \\
\text { coli }\end{array}$ & 3 & 2 & 3 & 2 & 2 & & & 1 & 1 & 2 & & & & \\
\hline $\begin{array}{c}\text { Klebsiella } \\
\text { pneumoniae }\end{array}$ & 2 & 2 & 2 & 2 & 2 & 1 & 1 & & & 1 & & & & 1 \\
\hline $\begin{array}{c}\text { Enterobacter } \\
\text { aerogenes }\end{array}$ & 2 & 2 & 1 & 2 & & & & & 1 & 2 & & 2 & & \\
\hline Total No. & 8 & 7 & 7 & 7 & 5 & 1 & 1 & 2 & 2 & 6 & & 2 & & 1 \\
\hline Total \% & & 87.5 & 87.5 & 87.5 & 62.5 & 12.5 & 12.5 & 25 & 25 & 75 & & 25 & & 12.5 \\
\hline
\end{tabular}

Results of this study about resistance of Bacillus isolates to antimicrobial agents were similar to those recovered from medicament [1] and clinical specimens [17]. Staphylococcus isolates were resistant to penicillins and this may be due to their ability to produce penicillinase enzyme or to change their PBPs. In this investigation, $S$. epidermidis had the highest number of muti-resistant isolates and these findings are in agreement with isolates obtained from a study using clinical specimens [18].

$S$. epidermidis may act as a reservoir for resistance which can be transferred to $S$. aureus. The transfer of resistance among different genera of Gram-positive and Gram-negative bacteria and between Bacillus species and staphylococci has been reported by many authors [19].

It is particularly noteworthy that the strain of $S$. aureus isolated in this study was resistant to beta-lactams, Te, and SXT, and these observations are in agreement with those of several studies of clinical strains [9] but disagree with studies of medicament strains reported by some other authors [1].

The high level of resistance to many antimicrobial agents shown by Gram-negative rods is well-known and has been reported with increasing frequency [20]. Klebsiella, E. coli, and Enterobacter are of increasing importance, as resistance to newer beta-lactams, particularly extended-spectrum beta-lactams, may be acquired by mutation in addition to plasmids $[21,22]$.

Resistance to beta-lactam antibiotics in Gramnegative bacteria can be due to four mechanisms: decreased permeability of the drug into the cell; hydrolysis of the drug by bet-lactamase; decreased affinity of the target penicillin-binding proteins (PBPs); and efflux pump mechanisms [22].

The major mechanism of resistance in bacteria causing clinically significant infection remains the expression of beta-lactamases, of which there are several classes including plasmid-encoded and chromosomally encoded enzymes [22].

$E$. coli and E. aerogenes isolates showed multi-resistance to beta-lactams and erythromycin. These findings are similar to those of investigations using clinical strains reported by several investigators [20]. Klebsiella spp. showed, in addition to these antibiotics, resistance to extended-spectrum beta-lactams (Ctx and Czx). These results are in agreement with those of studies with clinical strains reported by several authors [20]. The only isolate of $P$. aeruginosa from a topical medicament was multi-resistant to beta-lactams, gentamicin and erythromycin. This result is similar to investigations with clinical strains reported by several authors [20].

The results of this study indicate a high rate of resistance to antimicrobial agents of bacterial isolates from oral and topical medicaments, and this may indicate a widespread antibiotic resistance among bacteria isolated from different sources, including that of anthropological and environmental origin. 


\section{References}

1. de la Rosa MC, Mosso MA, Garcia ML, Plaza C (1993) Resistance to the antimicrobial agents of bacteria isolated from non-sterile pharmaceuticals. J Appl Microbiol 74: 570-577.

2. Gil MC, De la Rosa MC, Mosso, MA, Garcia Arribas ML (1986) Numerical taxonomy of Bacillus isolated from orally administrated drugs. J Appl Bacteriol 61: 347- 356.

3. van Doorne H, Boer Y (1987) Microbiological quality of hand filled hard gelatin capsule. Pharmaceutisch Weekblad 122: 820-823.

4. Ringertz O, Ringertz SH (1982) The clinical significance of microbial contamination in pharmaceutical products. Adv Pharmaceut Sci 5: 201225.

5. Spooner DF (1988) Hazards associated with the microbiological contamination of non-sterile pharmaceuticals, cosmetics, and toiletries. In Bloomfield. SF, Bair R, Leak RE, Leech R, editors. Microbial quality assurance in pharmaceuticals, cosmetics, and toiletries. Chichester: Ellis Horwood. 1534.

6. Baird RM (1991) Contamination of non-sterile pharmaceuticals in hospital and community environments. In Hugo Ed, Russell WB, editors. Pharmaceutical Microbiology. $4^{\text {th }}$ edn, Oxford: Black Sientific Publication. 381-391.

7. Anon (1988) Test for microbial contamination .In British pharmacopoeia, Appendix XVI London: HMSO. 195-200.

8. Anon (1990) Microbiological attributes of non-sterile pharmaceutical products .In United States pharmacopoeia, $22^{\text {nd }}$ edition, US Pharmacopeial Convention Inc., Rockville. 1684-1685.

9. Jones RN (2001) Resistance patterns among nosocomial pathogens: trends over the past few years. Chest 119: 397S-404S.

10. Gold HS (1996) Antimicrobial- drug resistance. NEJM 335: $1445-1453$

11. Levesque C, Piche L, Larose C, Roy PH (1995) PCR mapping of integrons reveals several novel combinations of resistance genes. Antimicrob Agents Chemother 39: 185-191.

12. Barrow GI and Feltham RKA (2003) Cowan and Steels' manual for identification of medical bacteria. 3rd edition. United Kingdom: Cambridge University Press.

13. Bauer AW, Kirby WM, Sherris JC, Turck M (1966) Antibiotic susceptibility testing by a standardized single disk method. Am J Clin Pathol 45: 493-496.
14. Clinical and Laboratory Standards Institute (CLSI) (2010) Performance standards for antimicrobial susceptibility testing. Approved standard M100-S17. Vol. 30, No. 1. Clinical and Laboratory Standards Institute, Wayne, PA. USA.

15. Gordon RE, Hayes WC, Pant CH (1973) The genus Bacillus. US Department of Agriculture: Agricultural Book No. 427. Washington, USA

16. Cotton DJ, Gill VJ, Mashall DJ, Gress J, Thaler M, Pizzo PA (1998) Clinical features and therapeutic intervention in 17 cases of Bacillus bacteremia in an immunosuppressed patient population. J Clin Microbiol 25: 672-674.

17. Verbist L (1991) Incidence of multi-resistance in Gramnegative bacterial isolates from intensive care units in Belgium: a surveillance study. Scand J Infect Dis Suppl 78: $45-53$.

18. Davies AL, Stone JW (1986) Current problems of chemotherapy of infections with coagulase-negative staphylococci. Europ J Clin Microbiol 5: 277-280.

19. Courvalin P (1994) Transfer of antibiotic resistance between Gram-positive and Gram-negative bacteria. Antimicrob Agents Chemother 38: 1447-1451.

20. Jarlier V, Fosse T, Philipon A (1996) Antibiotic susceptibility in aerobic Gram-negative bacilli isolated in intensive care units in 39 French teaching hospitals (ICU study). Intens Care Med 22: 1057-1065.

21. Chanal C, Sirot D, Romaszko JP, Bret L, Sirot J (1996) Survey of prevalence of extended spectrum $\beta$-lactamases among Enterobacteriaceae. J Antimicrob Chemother 38: 127-132.

22. Piddock LJV, Walters RN, Jin YF, Turner HL, Gascoyne-Binsi DM, Hawkey PM (1997) Prevalence and mechanism of resistance to third-generation cephalosporins in clinically relevant isolates of Enterobacteriaceae from 43 hospitals in the UK, 19901991. J Antimicrob Chemother 39: 177-187.

\section{Corresponding author}

Alaa H. Al-Charrakh

Department of Microbiology

College of Medicine/Babylon University

Hilla / Babylon Governorate, Iraq

Telephone: 009647813216822

Email: aalcharrakh@yahoo.com, ahani67@gmail.com

Conflict of interest: No conflict of interests is declared. 